\title{
SENSORY AND MOTOR NERVE CONDLCTION VELOCITY IN LONG-TERM DIPHENYLHYDANTOIN THERAPY
}

\author{
José H. Xavier de Castro \\ Mario L. Acosta \\ RGBERTO E. P. SicA \\ NELLY Guercio
}

Since Merrit and Putnam (1938) 8 introduced the diphenylhydantoin $(\mathrm{DPH})$ in the treatment of epilepsy, it has keen used largely as the main drug in many forms of the disease.

Several attempts have been made to demonstrate its action on the peripheral nerve, but the obtained results are controversial. Korey ${ }^{6}$ first, and Morrell, Bradley and Ptashne" after, gave experimental evidence of DPH toxic effect on the nerve. Histologically Guercio, Sica, Taratuto and Poch: demonstrated a demyelinating effect on the peripheral nerve of men which was correlated with prolonged administration of the drug.

Brumlik and Moretti ${ }^{2}$ failed to demonstrate any abnormality in motor or sensory nerve conduction velocity in patients under DPH therapy; however Hopf ${ }^{5}$ found slowing of slowly motor conduction nerve fibres, while others $1,3,7$ found a slowing of the maximum nerve motor conduction velocity, which suggest that the fastest fibres in the nerve are damaged as well.

We now wish to repurt our findings in epileptic patients under DPH therapy. The background of this investigation was to estimate the motor and sensory conduction velocities in the median nerve, in an attempt to elucidate further the effect of $\mathrm{DPH}$ on peripheral nerve.

\section{MATERIAL AND METHOD}

Eleven epileptic patients, 5 males and 6 females, aged between 17 and 52 years, were submitted for electrophvsiological investigation. All of them were under $\mathrm{DPH}$ therapy mainly, however other anticonvulsivant drugs were employed. The length of treatment varied between 3 and 18 years. Other causes of neuropathy, such as diabetes, uremia, alcoholic intoxication were excluded.

Twenty subjects, 5 males and 15 females, aged between 19 and 46 years, in good health at the time of the experience and without history of any neurological disorder, were employed as controls for median nerve sensory conduction velocity.

Fourteen subjects, 4 maies and 10 females, aged between 18 and 53 years, in good health and without history of neurological disturbance, acted as controls for median nerve maximum motor conduction velocity.

Trabalho realizado no Serviço de Neurologia (Chefe: Dr. Gustavo Poch) do Hospital Ramos Mejia, Buenos Aires, Argentina. 
The recording electrode was a silver foil $2 \mathrm{~cm}$ long and $0.5 \mathrm{~cm}$ wide covered with a felt pad soacked in saline solution attached to the skin previously prepared with eiectrode jelly, of the medial aspect of the wrist, over the median nerve (Fig. 1). The reference electrode was similar to the recording one and was fixed to the skin of the medial aspect of the wrist $2 \mathrm{~cm}$ proximal to the recording one (Fig. 1).

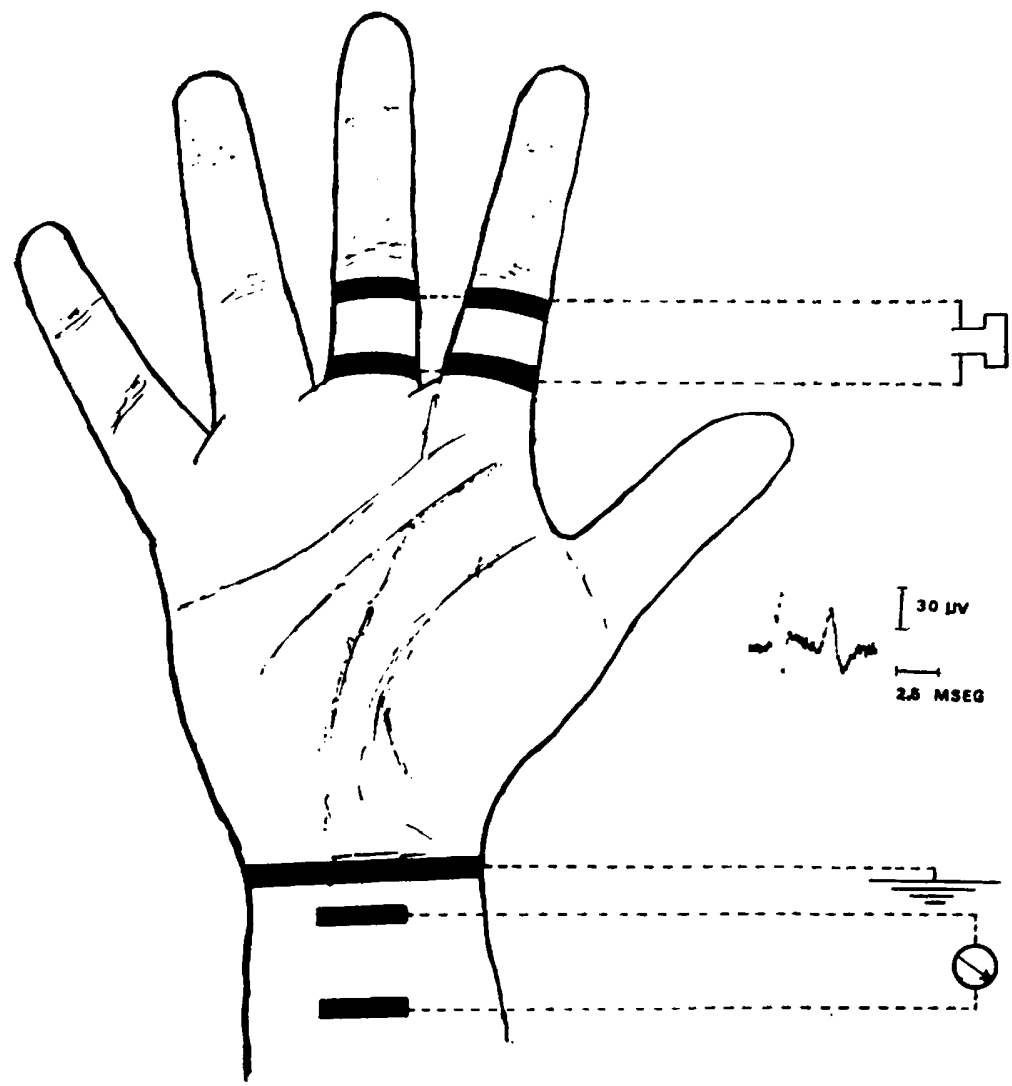

Figure 1 - In the wrist: recording electrode, reference electrode and earth electrode. In the $2 n d$ and 3 rd fingers are the stimulating electrodes.

The earth electrode was a silver foil $5 \mathrm{~cm}$ long, $0,5 \mathrm{~cm}$ wide, coated with electrode jelly and attached to the medial aspect of the wrist, which had been prepared with electrode jelly previously, by a plastic band between the recording electrode and the stimulating cathode (Fig. 1).

A DISA coaxial needle electrode, type 9013K0031, was inserted in the abductor pollicis brevis muscle lor recording motor conduction velocity.

For nerve sensory conduction velocity the stimulating electrodes were 4 silver foils, $7 \mathrm{~cm}$ long and $0.4 \mathrm{~cm}$ wide, coated with electrode jelly, wrapped round the 
first phalanx of the 2nd and 3rd Pingers (Fig. 1), with the cathode proximal. Previously, the skin of the phalanx was prepared with electrode jelly.

For motor conduction velocity, the stimulating electrodes were a pair of chloride silver screws, which were covered by felt pads soacked in saline.

Experimental procedure - Nerve sensory conduction velocity: once the electrodes were attached to the skin, the subject was encouraged to relax, then the stimulus intensity was increased progressively until the first evoked potential of the median nerve could be seen. The vaiue of the stimulus intensity, in volts, at this moment, was regarded as theshold. Then, the stimulus intensity was increased again until the maximal amplitude of the evoked median nerve potential was observed, then the stimulus intensity was made supramaximal by $10 \mathrm{~V}$ and 10 succesive records were obtained.

The stimuli were square pulses, $0.5 \mathrm{msec}$ duration, delivered from a Multistim stimulator, type 13G04, at a range of about one every 2 or 3 seconds.

The potentials were displayed on the screen of a 3 channels DISA electromyograph. type 13A69, and all of them were photographed. The measurements were made on the prints.

Maximum motor nerve conduction velocity was measured following the technique described by Hodes, Larrabee and German 4.

The ambient temperature was maintained in all the experience over $25^{\circ} \mathrm{C}$.

Treatment of the results - Ten records of sensory nerve conduction velocity were obtained in each subject, the results were pooled and the mean and the standard deviation of each one was calculated. Throughout the text means are given with their standard deviation. Difference between means was calculated using the "Student" $t$ test. Correlations were estimated by the Pearson correlation coefficient ( $r$ ).

\section{R E S U L T S}

Figure 2 shows the individual values of maximum motor conduction velocity obtained in patients and controls. Eight patients $(\mathbf{7 2 . 5 \% )}$ were below the lower limit of the control group, showing a slowing of the fastest conducting motor nerve fibres. Furthermore, the mean motor conduction velocity of the whole patients group was significantly different from the control group (Table 1). Apparently the slowing of conduction velocity in the motor fibres was negatively correlated with the length of treatment $(\mathrm{r}=-0.74 ; \mathrm{P}<0.01)$, but not with the dayly employed dosis $(\mathbf{r}=0.38 ; \mathrm{P}>0.1)$.

Figure 3 shows the individual values of nerve sensory conduction velocity, obtalned in each subject. It can be seen that 8 patients $(72.5 \%)$ are below the lower limit of the control population. The mean value of patients group was significantly smaller than the control group (Table 1). The conduction velocity of the sensory fibres is positively correlated with the conduction velocity of the fastest motor nerve fibres $(\mathrm{r}=0.87 ; \mathrm{P}<0.001)$ and negatively correlated with the length of treatment $(r=-0.76 ; \mathrm{P}<0.01)$ but not with the dayly dosis $(\mathrm{r}=0.25 ; \mathrm{P}>0.1)$. As it can be expected from the above results, the mean sensory latency in patients group was significantly larger than the control group (Table 1).

On the other hand, the mean threshold for sensory conducting fibres was, as well, significantly different from the control population (Table 1), in spite that all the values, except 2 , were in the control range and was not correlated with the slowing of sensory conduction velocity $(r=0.20 ; P>0.1)$.

The mean amplitude of the median evoked potential, measured pick, in the affected group was not significantly different from the control group (Table 1), and was not correlated with the slowing of the sensory conduction $(r=0.36 ; P>0.1)$, although three patients were below the low limit of the control group. 
M/SEG

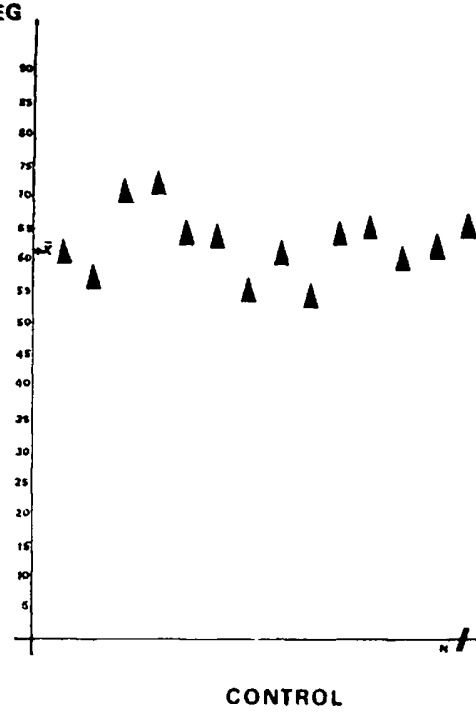

M/SEG

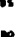

$\infty$

ro

66

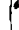

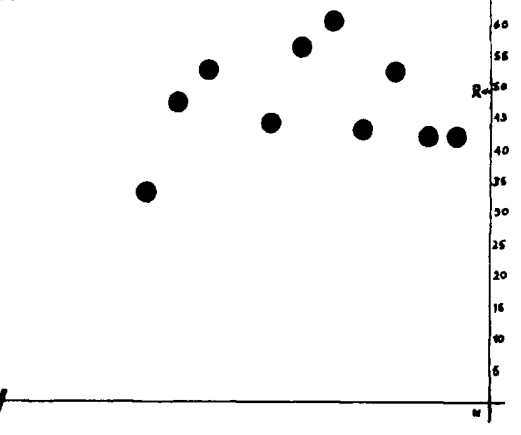

PRosante

Figure 2-Individual values of motor conduction velocity in patients and controls: $n=$ number of cases.

\begin{tabular}{|c|c|c|c|c|c|}
\hline & \multicolumn{2}{|c|}{ CONTROLS } & \multicolumn{2}{|c|}{ EPILEPTICS } & \multirow{2}{*}{$P$} \\
\hline & range & mean & range & mean & \\
\hline $\begin{array}{l}\text { Sensory } \\
\text { conduction } \\
(\mathrm{m} / \mathrm{sec})\end{array}$ & $47-67$ & $\begin{array}{r}53.53 \\
\pm 1.72\end{array}$ & $41-54$ & $\begin{array}{r}45.60 \\
+1.24\end{array}$ & $<0.001$ \\
\hline $\begin{array}{l}\text { Motor } \\
\text { conduction } \\
(\mathrm{m} / \mathrm{sec})\end{array}$ & $53-71$ & $\begin{array}{r}62.00 \\
\pm 4.80\end{array}$ & $33-68$ & $\begin{array}{r}49.00 \\
\pm 9.83\end{array}$ & $<0.001$ \\
\hline $\begin{array}{l}\text { Sensory fibres } \\
\text { threshold } \\
\text { (V) }\end{array}$ & $16-44$ & $\begin{array}{r}23.80 \\
\pm 3.03\end{array}$ & $18-50$ & $\begin{array}{r}34.60 \\
\pm 2.73\end{array}$ & $<0.001$ \\
\hline $\begin{array}{l}\text { Sensory } \\
\text { latency } \\
\text { (msec) }\end{array}$ & $1.9-2.6$ & $\begin{array}{r}2.41 \\
+0.05\end{array}$ & $2.2-3.1$ & $\begin{array}{r}2.84 \\
\pm 0.02\end{array}$ & $<0.001$ \\
\hline $\begin{array}{l}\text { Sensory potential } \\
\text { amplitude } \\
(\mu \mathrm{V})\end{array}$ & $18.6-54.3$ & $\begin{array}{c}29.1 \\
\pm 3.12\end{array}$ & $9.4-47.5$ & $\begin{array}{r}26.3 \\
\pm 1.15\end{array}$ & $>0.7$ \\
\hline
\end{tabular}




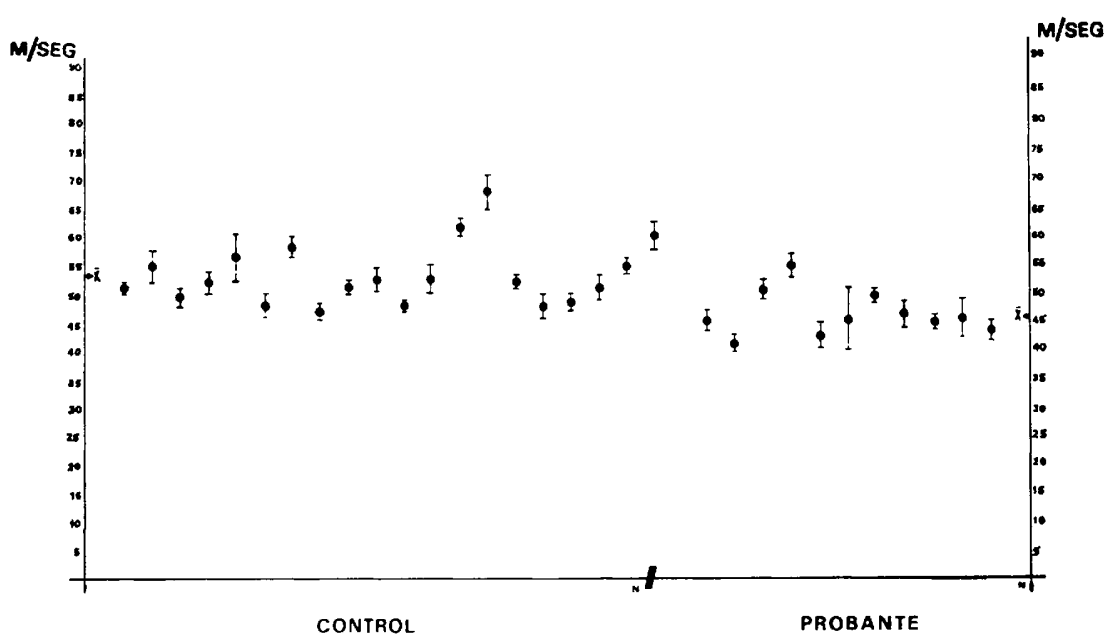

Figure $s$ - Individual values of sensory conduction velocity in patients and controls: $n=$ number of cases.

Slowing of the fastest nerve motor fibre has been demonstrated previously by several authors $1,3,5,7$ in $\mathrm{DPH}$ treated patients. The present results show that the damage of the motor axons seems to be correlated with the length of theatment, but not with the dayly employed dose. Similar results have been obtained with the sensory nerve conduction velocity, allowing us to assume that $\mathrm{DPH}$ has not a selective effect on motor or sensory fibres and that the drug needs to be acting on the nerve for long periods, at least when it is administrated at therapeutical doses, to produce damage on it.

Another fact is the teidency to increase the sensory nerve fibre threshold in patients group which accounts for a further abnormality of the fibre.

The lack of significant difference in the mean amplitude of the sensory evoked potentials between the affected and control groups, could signify that most of the sensory axons are not really destroyed, but disturbed in some way to become slower.

\section{S U M M A R Y}

Eleven epileptic patients under long-term DPH therapeutical doses were studied and the obtained results allow us to postulate that DPH, when is administrated for long periods, can produce damage of the peripheral nerve by involvement of the sensory and motor fibres in a similar degree. 


\section{R E S U M O}

\section{Velocidade de conduçãs sensitiva e motora no tratamento prolongado com a difenilidantoina}

Para avaliar as velocidades de condução sensitiva e motora no nervo mediano, foram utilizados 11 pacientes epilépticos submetidos a tratamento prolongado com a difenilidantoina, administrada em doses terapêuticas. Os resultados obtidos foram correlacionados com grupos controles. Estes resultados mostraram significativa diminuição das velocidades de condução sensitiva e motora, que estavam relacionadas com o tempo de tratamento e não com a dose diária empregada. Conclui-se que a DPH, em administração prolongada, cltera a condutibilidade motora e sensitiva nos nervos periféricos.

1. BIRKET-SMITH, E. \& KROGH, E - Motor nerve conduction velocity during diphenylhydantoin intoxication. Acta Neurol. Scandionav. 47:265, 1971.

2. BRUMLIK, J. \& MORE'iTI, L. - The effect of diphenylhydantoin on nerve conduction velocity. Neurology (Minneapolis) 16:1217, 1966.

3. GUERCiO, N.; SICA, R. E. P.; TARATUTO, A. \& POCH, G. F. - Neuropatía por hidantoínas. Pren. méd. argent. 55:1280, 1969.

4. HIODES, R.; LARRABEE, M. C. \& GERMAN, W. - The human electromyogram in response to nerve stimulation and the conduction velocity in motor axon. Arch. Neurol. Psychiat. (Chicago) 60:340, 1948.

5. HOPF, H. C. - Effect of diphenylhydantoin on peripheral nerve in man. Electroenceph. clin. Neurophysiol. 25:393, 1968.

6. KOREY, S. R. - Effect of Dilantin and Mesantoin on the giant axon of the squid. Proc. Soc. Exp. Biol. a. Med. 76:297, 1951.

7. LOVELACE, R. E. \& HORWITZ, S. J. - Peripheral neuropathy in long-term diphenylhydantoin tierany. Arch. Neurol. Psychiat. (Chicago) 18:69, 1968.

8. MERRITT, H. H. \& PUTNAM, T. J. - Sodium diphenylhydantoin in the treatment of convulsive disorders. J.A.M.A. 111:1068, 1938.

9. MORRELL, F.; BRADLEY, W. \& PTASHNE, M. - Effect of diphenylhydantoin on peripheral nerve. Neurology (Minneapolis) 8:140, 1958.

Dr. José H. Xavier de Castro present address: Instituto de Neurocirurgia Hospital São Francisco - 90000 Porto Alegre, RS - Brasil. 